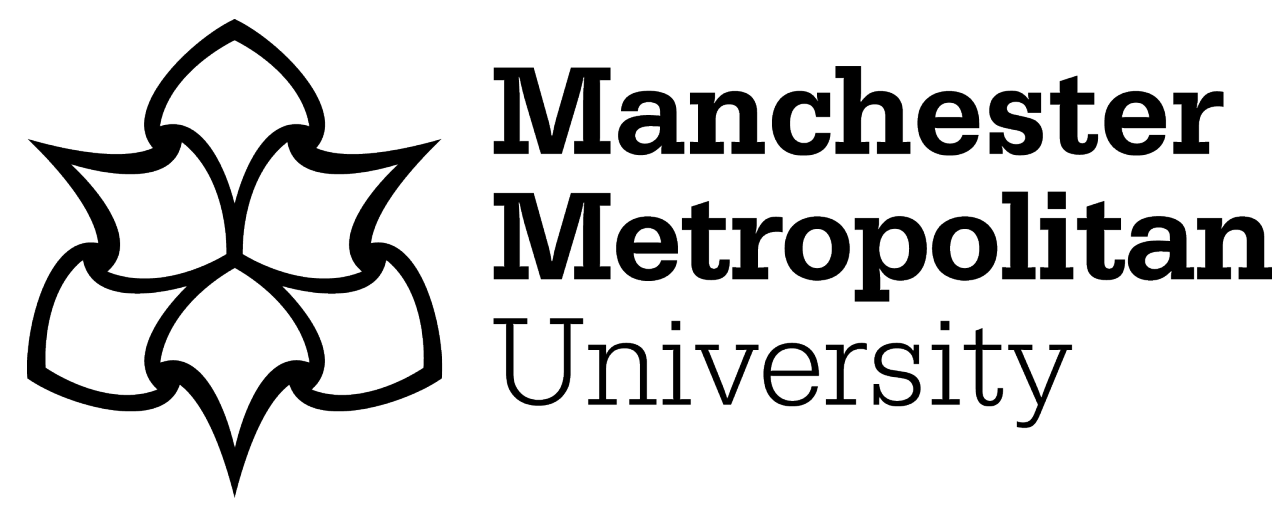

Richardson, Tina (2019) Hiding the Bodies: Geographic Repression in Higher Educational Space. Space and Culture, 22 (4). pp. 460-473. ISSN 1206-3312

Downloaded from: https://e-space.mmu.ac.uk/621084/

Version: Accepted Version

Publisher: SAGE

DOI: https://doi.org/10.1177/1206331217751777

Please cite the published version 


\title{
Hiding the Bodies: Geographic Repression in Higher Educational Space
}

\author{
Tina Richardson
}

\begin{abstract}
This article critiques the way that universities have acquired and developed campus space since World War II. Prompted by the need to increase student entry, British universities grew exponentially, with a demand to expand the campus in order to provide more teaching space and student accommodation. This article looks at the side effects of this expansion by providing a case study that demonstrates that land acquisition can have a deleterious effect on local residents. Using theories from urban studies, postmodern geography and cultural theory, this article presents the case study through a transdisciplinary lens, offering an original analysis of the heritage of an inherited cemetery.
\end{abstract}

\section{Keywords}

campus planning, social history, capitalism, urban regeneration, burial land

During the major development of the University of Leeds (UK) campus in the 1960s, the university became the Trustee for a cemetery that had previously been adjacent to the campus. Located in the north of the campus today, the cemetery dates back to 1833 , prior to which it was a greenspace known as St George's Field. Between 1833 and 1969 it was a working cemetery. Throughout its history St George's Field has been a paupers' graveyard and also a private cemetery whereby local people could buy shares in order to secure their burial plots, going through a number of name changes during this time. During the $1960 \mathrm{~s}$ campus development programme - overseen by the architects and master planners Chamberlin, Powell and Bon (CPB) - the cemetery became a place of tension and controversy when the university took over the cemetery and removed most of the gravestones (figure 1 shows one of the remaining pockets of gravestones). This involved a politico-legal battle between the University of Leeds and the relatives of the dead in regard to this burial space. 


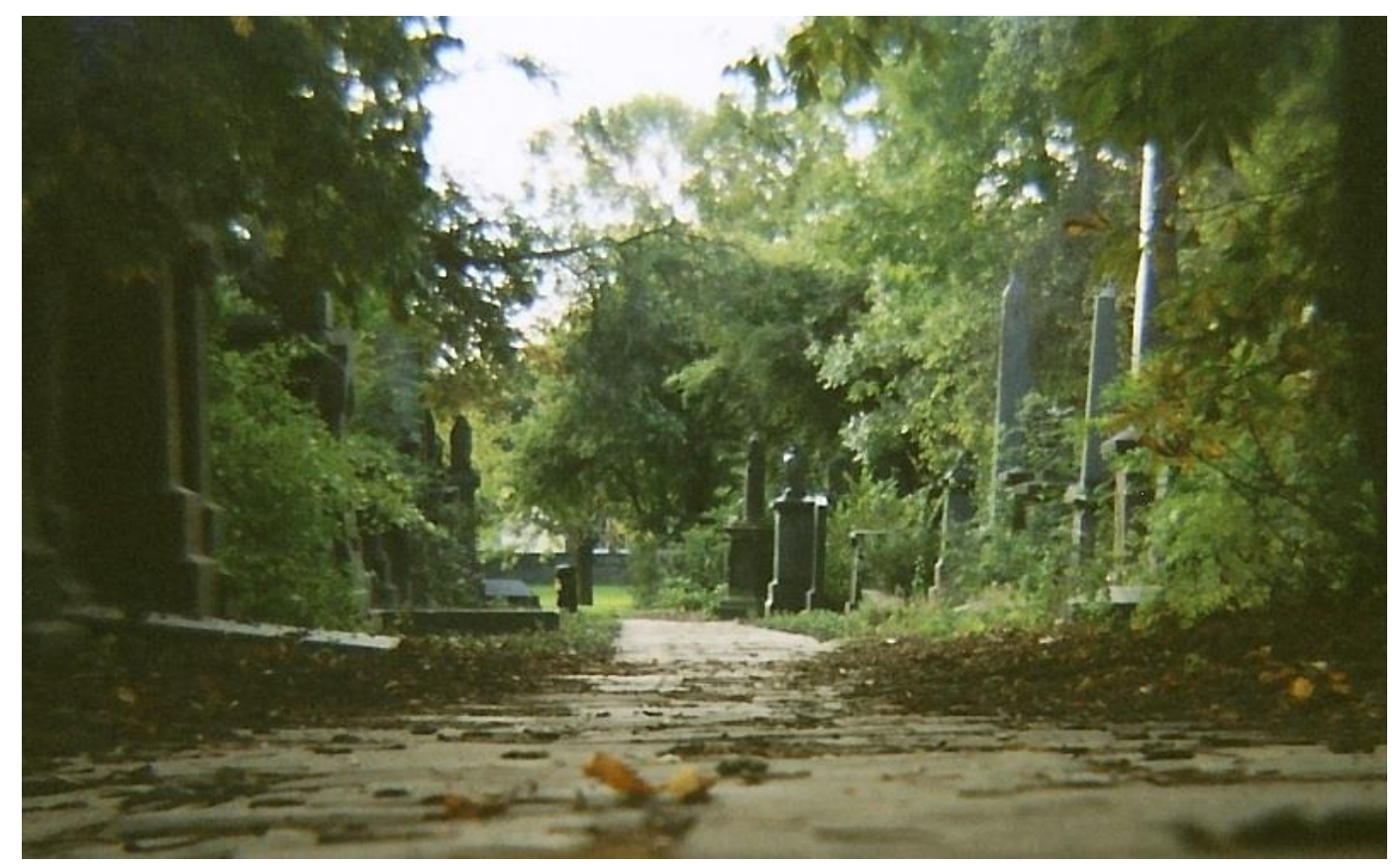

FIGURE 1. Some of the remaining headstones and memorials in a section of St George's Field. These grave markers are located either side of a path in the north part of the cemetery. (C) Tina Richardson

This article will discuss what I describe as an act of 'hiding' that goes to the very bones of the discourse of the university in regards to the burial ground. I maintain that at the time of the acquisition, this hiding was around the concept of creating order out of chaos, since the cemetery was in a very poor state. However, in subsequent years the hiding has changed to one of a reluctance to openly share and discuss the heritage of the space, since this also means an exhumation of the disputes that occurred at this time. While the university is happy to celebrate the heritage of the modernist buildings from the 1960s (a number which now have heritage status), the cemetery is not celebrated at all and not even considered to be a heritage site by the university, despite having a blue plaque outside it and a few within the space itself, which are dedicated to specific individuals of note.

By incorporating cultural and socio-spatial theory, I will explore the repercussions of this concealment, such that it is based on institutional shame that comes about through fear and a resistance to wholeheartedly embrace the space itself and its difficult past. ${ }^{1}$ By providing examples, I suggest that this is a form of geographical repression that negates a significant portion of the historical past of this space. What Michel Foucault describes as other spaces, in particular heterotopias, these sites have the effect of being at once fabulations and at the same time real spaces that may be under dispute. They do not sit in neatly packaged and easily definable categories, rather more shifting like a mirage depending on the perspective you take 
on them. These spaces often appear as representations which are designed to accommodate a lack in some way. However, through this act of compensation something is repressed while at the same time reaffirmed. These tensions are apparent in the case study of St George's Field.

The university had declared an interest in acquiring the site as far back as 1922, anticipating its closure as a cemetery and the possibility of being its future caretakers (Fletcher 1975: 100). The issue was raised again in 1947 and 1953, but it was not until 1955 that discussions began in earnest, when it was revealed that the cemetery company was having financial difficulties (Fletcher 1975: 102). ${ }^{2}$ In 1956, in a letter to the university's solicitors, the Bursar of the university described the hopes of the university obtaining the cemetery land as being "a real acquisition" (while a draft letter to be sent to shareholders at the same time stated that there were plans for it to be "a quiet cloister", apparently this was removed from the final circular) (ibid.). Shortly after this, and in order to become the majority shareholder, the university offered to buy the cemetery company shares from the current owners (those who had previously purchased burial plots) at $£ 1.50$ for every $£ 10.00$, with a requirement that three quarters of those with shares took up the offer (ibid). Thus began the process of acquiring the land.

By 1957 all but sixteen of those with shares had transferred them to the university (although this number was made up of fourteen people whose addresses were not known) (Fletcher 1975: 102). So, it appears, only two people (or two families) were originally resistant to the transfer of cemetery space to the university. There are letters that exist in the university archives that contest the amount recommended for compensation, such as one from Mrs. M. J. Chapman to the university bursar. Chapman stated that if one wanted to provide a new grave place "you would have to pay more for the same" and that the $£ 40$ was not "true compensation" (1973: 1-2). Nevertheless, the transfer went ahead. Once the university became the Trustee of the cemetery, it then became apparent that the task they had set themselves was far greater than expected, especially with the inadequate budget they had allowed (£45,000 in 1964), in regard to the state of the cemetery at that time (Fletcher 1975: 104).

A letter from the London Necropolis Company Limited to the University of Leeds, dated 23 May 1967, provided advice on how the university should technically carry out the planned work, but also expressed caution in the university's approach to the landscaping project: "Experience has shown that the treatment of burial grounds is one of those subjects which in 
the press and local gossip is "dynamite" (Richardson 1967: 3). However, what started out as a project that involved no gravestones being disturbed and for them all to be maintained, ended up being one whereby most would be removed in order to create an open space. ${ }^{3}$ It was at this point that the university - whose previous two dissenters had posed no serious threat at the time of the share transfer - realised that local opposition could be a problem and that an Act of Parliament was the only practical route.

Fletcher said, while many supported the project, there were also "[m]any bitter and some pathetic letters...sent to the University, to the press and to the local Members of parliament" (1975: 104). A letter sent by a Miss Ottley expressed her concern that once the project was over, people would forget about the local opposition at that time, and the reasoning behind it, and the university would eventually be able to use the space in any way they chose (cited in Fletcher 1975: 105). What is evident about Miss Ottley's comments, is they reflect how history and space works in this regard, through a process of hiding and forgetting.

While doing my initial research on St George's Field (2009-2013), the link that appeared highest in university website searches was one from the Equality Services Department at the university, which connected to the BBC's website. This link took you to a BBC article dated 25 April 2006 under a section on Leeds Local History. Today this link no longer appears in the first few pages of a search for either 'St George's Field' or 'cemetery' on the university website, although the actual BBC link is still active (BBC 2006). This article is entitled 'Life and Death in Leeds' and takes you to two sound files which are recordings from the event of the unveiling of the blue plaque on the gatehouse in 2006 (see figure 2). The sound files feature Dr. Kevin Grady from Leeds Civic Trust who attended the unveiling. The article begins: "Now hidden within the campus of the university the Leeds General Cemetery Company's site at St George's Field is an important piece of Leeds' Victorian history" (BBC 2006). Grady's use of the word "hidden" is a key signifier in regard to this under-advertised space. 


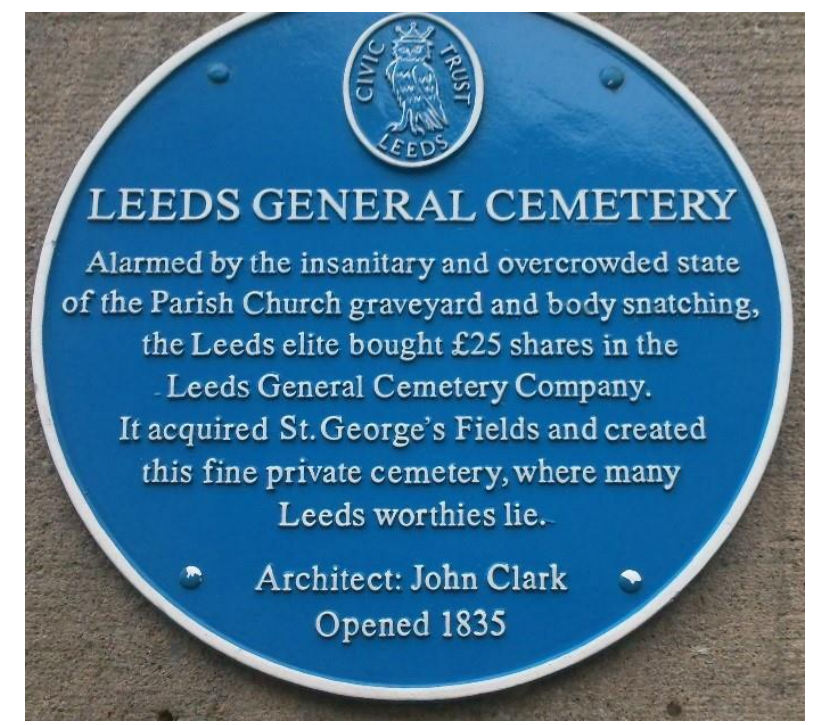

FIGURE 2. A Blue Plaque in St George's Field 2016. Located the gatehouse entrance, the plaque says: "LEEDS GENERAL CEMETERY/Alarmed by the insanitary and overcrowded state of the Parish Church graveyard and body snatching, the Leeds elite bought $£ 25$ shares in the Leeds General Cemetery Company. It acquired St George's Fields and created this fine private cemetery, where many Leeds worthies lie./Architect: John Clarke/Opened 1835". (C) Tina Richardson

In the period I have been researching the university campus, it is apparent that the university is very proud of some of its heritage. For example, in 2010 they celebrated the grade II listing of a number of the Brutalist buildings from the period of CPB. However, the cemetery, with its complicated palimpsest geography - enclosed behind four walls and with the surface appearance of a pleasing landscaped park - is an unacknowledged history. Much effort is required to find the university documents behind its transformation. I maintain it behoves the university that the bureaucracy and the geography are not too readily connected. Paul R. Mullins and Lewis C. Jones recognise that this is not an uncommon issue with universities and campus expansion. When these types of situations arise, they propose an archaeological approach to the university campus involving a multitude of "stakeholders", including the relatives of previous local residents who may have lived on what now appears as university space (Mullins and Jones 2011: 251). They go on to say that campus archaeology "illuminates the strategically unrecognized privileges that makes mass displacement possible and confronts the ways many universities continue to clumsily negotiate their complicity in mass removals while they aspire to grow further" (ibid.). Mullins and Jones emphasise the importance of research in the area of university campuses in helping to make visible what has remained hidden. (ibid.).

One cannot understate the importance of cemeteries to people and the personal value 
attributed to the place that their loved ones are buried. But they are also a barometer of a given cultural moment, in regards to how they evolve over time:

Burial sites are centrally significant to a community's sense of well being and indirectly, to the preservation of history by teaching the living about the past. A cemetery is a living place that reflects the conditions and social realities of the surrounding community both past and present. (Miller and Rivera 2006: 334)

At the University of Leeds the cultural attitude during the 1960s reflects both the concern of the families whose relatives are buried there, but it also reflects the rationalist approach to the planning that was undertaken on the campus, resulting in the tabular rasa effect that now appears as the park itself.

The University of Leeds utilised the British legal system to work around their reneging of their promise to maintain the grave plots for the families of those interred in St George's Field. The completed project resulted in the removal of most of the gravestones, with the still-living relatives unable to exactly locate their deceased family members. At the time a large map of the cemetery, with every burial space indexed and marked, was created (it is still available in the university library). However, in a practical sense it would require that a visitor attempting to locate a grave would be able to translate the measurements on the map into real space. One such relative, Christine Bairstow (whose twin sister, Pauline Mavis White, is buried there and died when they were 6 months old), demonstrated to me how difficult this was: in the space that is now a grassy area, with surrounding trees but no headstones nearby, Christine was only able to gesture to a general area, having now marked the area at the base of a nearby tree with a memorial of her own, even though the tree is a good few feet away from where she believes her sister is buried (see figure 3). 


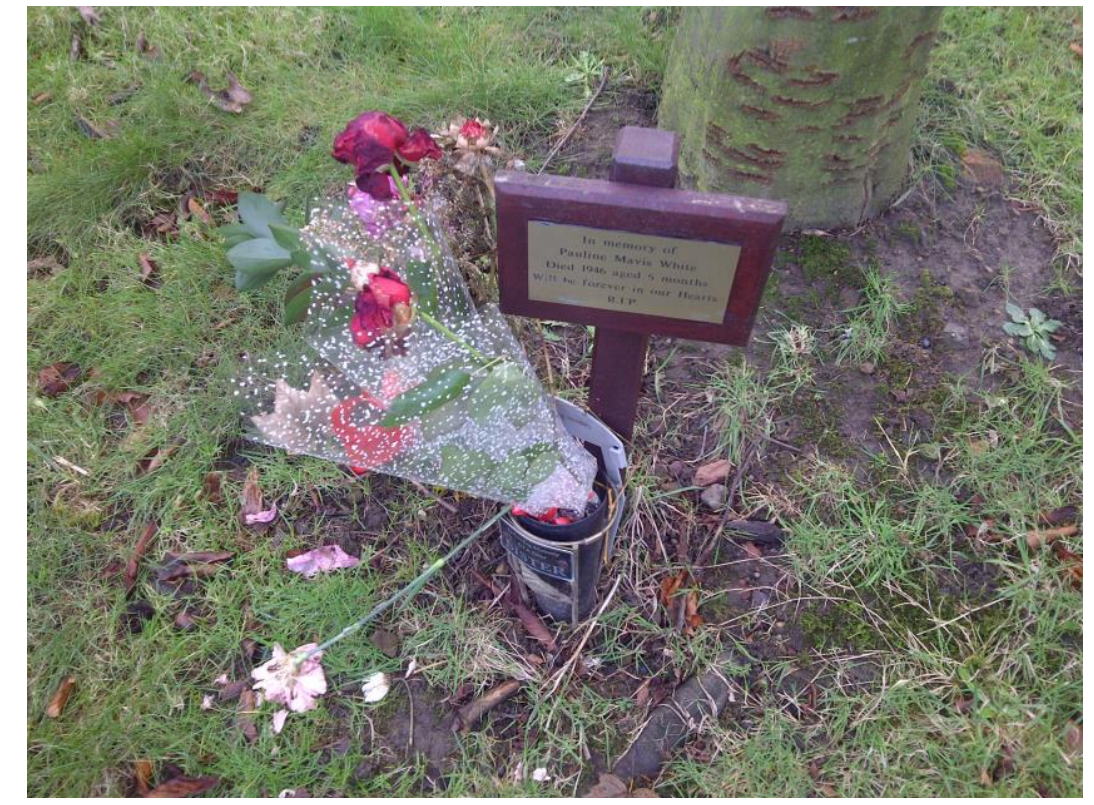

FIGURE 3. This recent memorial has been placed in St George's Field as a marker of the grave of Pauline Mavis White by her twin sister, Christine Bairstow. @ Tina Richardson

While it is the case that the families are still allowed to visit the plot of their relative's grave, the marker of the body has been removed in nearly all cases. This demonstrates that a transfer of territory has taken place. Not just in the sense that the university became responsible for the cemetery as a whole, therefore a transfer of care or ownership, but because of the removal of the index of the bodies: the gravestone. Although this may not be equated to the types of dispossession that has occurred on the level of colonialism (or more recently in larger neoliberalist practices appearing under the rubric of urban regeneration), for those individuals involved, dispossession is quite likely the effect of this territorial transfer. Mullins and Jones remark on a similar exercise carried out by the Indiana University Medical Centre in 1921, whereby plans to extend the campus involved graves in the garden of one of the oldest homes in Indianapolis. While the university hospital at Indiana was initially unwilling to destroy this historical place, eventually a bulldozer was used and the home and graves replaced with a memorial boulder (Mullins and Jones 2011: 253).

As well as general clauses contained in the University of Leeds Act 1965 that enable much breadth of interpretation, some clauses are very specific in defining the powers that the university has with regard to the cemetery. Clause 5.-(2) (a) states: "the University may... enclose it or any part thereof or keep it or any part thereof enclosed by walls, railings or fences, and gates" (1966: CH. xix, 4). This eventually involved the closing and moving of the original entrance arches. Even though they remain, the arches have been closed to the extent 
that they no longer provide entrances to the space (one is blocked in with bricks and the other is placed within the actual cemetery boundary for decorative purposes), consequently adding to the hiding of the cemetery (see figure 4 and 5).

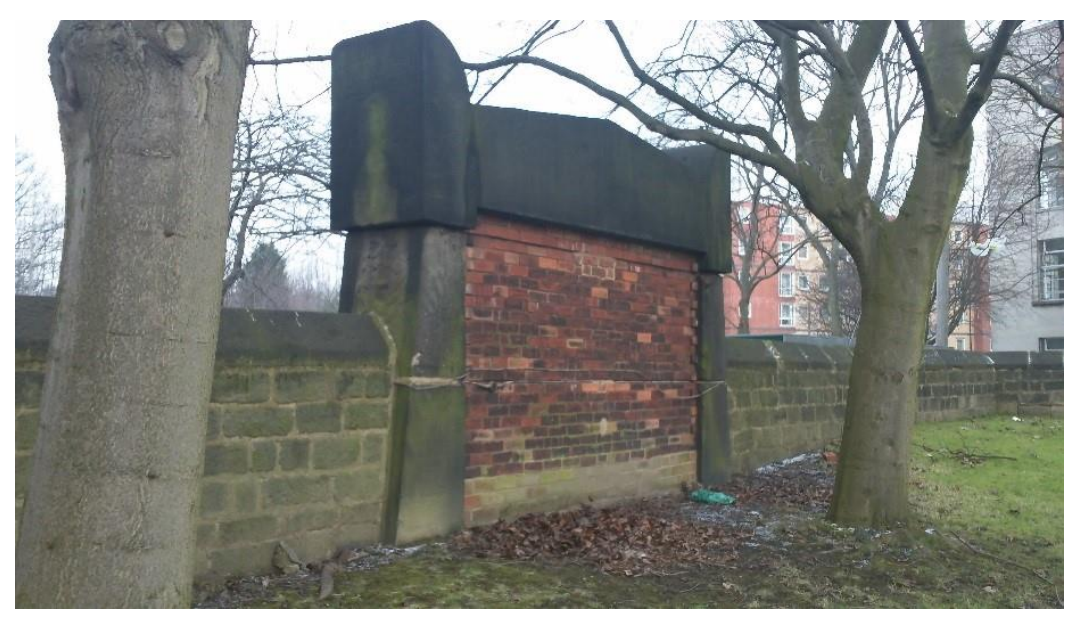

FIGURE 4. Free-standing Arch in St George's Field 2014. This arch is close to the Henry Price Halls of Residence, which overlooks the cemetery. At the top on the left you can see under the overhang of the building and directly on the left is the original wall of the cemetery on which the halls sits in a cantilever effect. @ Tina Richardson

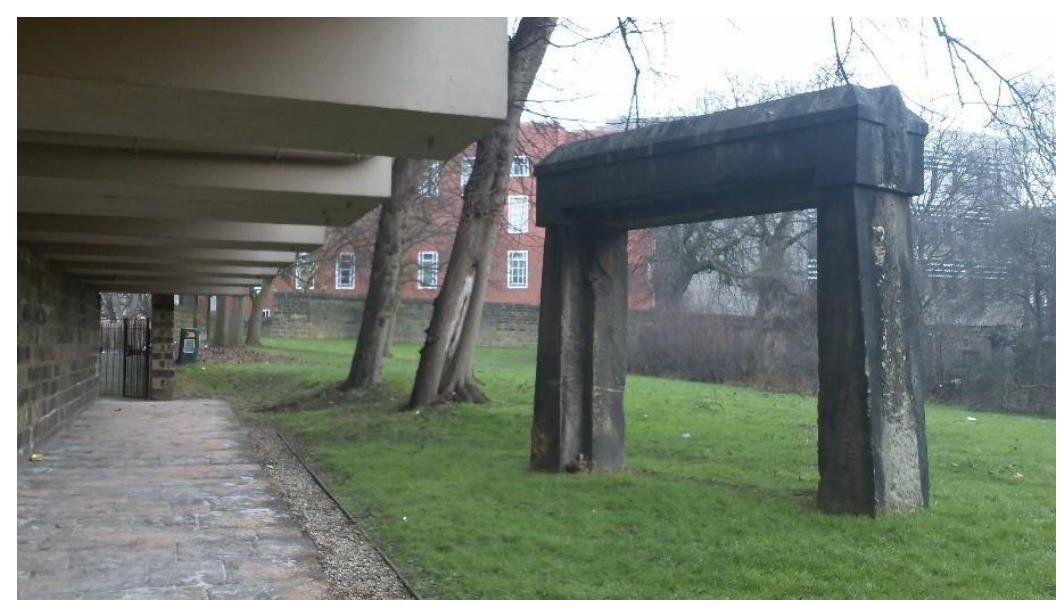

FIGURE 5. Filled-in Arch in St George's Field 2014. This arch forms part of the cemetery wall and faces onto Clarendon Road and an area known as Woodhouse Moor. There is also a campus vehicle exit road nearby, Cemetery Road. The building on the left is the Henry Price halls of residence. ( ) Tina Richardson

The phenomenon of hiding is often a side-effect of rationalist spatial organisation and planning. Raphaël Fischler says that planners set "norms" that allow particular situations to be assessed within a particular framework (1995: 19). A professional space is carved out which contains specific phenomena, enabling various judgements to be made about a given situation (1995: 20). Fischler states that the analysis of planning documents helps to reveal the "culture of planners" in relation to economics and the social repercussions of their 
actions, and this means the ideologies and practices behind institutional development appear in the form of programmes which have specific material and social effects in regard to what will be carried out (1995: 22). This is what Foucault refers to as a "regime of rationality".

It is contingent on the plan that its objectives are evaluated in the light of the mission supporting the plan. This is its mandate. While this might sound simple - fulfilling a mission which is clearly set out - it is far from it, since there are many components that have to be considered, influenced, negotiated and, where necessary, dominated. Henri Lefebvre says that in the institution, "bureaucratic space...is at loggerheads with its own determinants and its own effects: though occupied by, controlled by, and oriented towards the reproducible, it finds itself surrounded by the non-reproducible - by nature, by specific locations, by the local, the regional, the national and even the worldwide" (1991: 349-50). This is where it becomes clear how power has to be continually renegotiated in order for plans to be put into action. Lefebvre states this eloquently when demonstrating the fluidity of space and how really it does not have a straightforward phenomenological manifestation: "space is neither a 'subject' nor an 'object' but rather a social reality - that is to say, a set of relations and forms" (1991: 116).

St George's Field is what Lefebvre describes as an abstract space of social and political significance whereby "The space of a (social) order is hidden in the order of space" (1991: 289), (Lefebvre's italics). He goes on to explain how some people are advantaged by certain spaces and others are omitted from them, with this bringing about a "violence" through arrangements that are deemed "rational" (ibid.). In acquiring the cemetery the university has changed the space of the past, while at the same time making it part of its future plans by rationally integrating it into institutional space.

The landscaping of the cemetery carried out by the university, with the help of the relevant Parliamentary Act, involved a process of hiding that involved material forces, capital processes and shifting social relations. Today the space looks innocuous: it is a lovely landscaped space which, if you can find it, invites you to walk its paths or, in the summer, gather on the grassy areas with friends. But, as Lefebvre states of social spaces:

The illusion of transparency goes hand in hand in hand with a view of space as innocent, as free of traps or secret places. Anything hidden or dissimulated - and hence dangerous - is antagonistic to transparency, under whose reign everything can be taken in by a single glance from that mental eye which illuminates whatever it contemplates $(1991,28)$. 
The alteration of cemetery space to that of university park is part of the project of the postmodern neoliberal university and it advantaged it to both include the cemetery space in its portfolio and to 'hide' the consequences of that acquisition. What is not represented (and what is) is both a cause and effect of ideology: "what we call ideology only achieves consistency by intervening in social space and in its production [which] consists primarily in a discourse upon social space" (Lefebvre 1991: 44).

In the opening to her essay on the regeneration project at Grand Central Station in New York during the 1990s, Cindi Katz states: "it is clear that the spatial forms associated with increasingly globalized capitalist production are indeed masterful at hiding the consequences and contradictions of the social relations associated with it" (2001: 96). Katz examines the privatisation of space as it pertains to the neoliberalist project. She specifically looks at the policies behind Broken Window Theory, broken windows being a sign of social disorder, with a removal of those signs being a way of improving the aesthetics of area (as adopted by the mayor of New York, Rudy Giuliani, in the 1990s). Commenting on the complexity of these types of spaces, and their implicit heterogeneity, Katz discusses the partitioning of space through "domination and privilege" (2001: 94) and describes the work of the Grand Central Partnership, in its "cleaning up" of this area of New York, as a heterotopia of compensation (2001: 102). The policy also involved 'moving on' the homeless in order to remove them from the sight of commuters and shoppers in the area. Katz uses terms such as "reordering", "regulation" and "sanitation" when discussing the rhetoric attached to the project (ibid.). She states that this compensatory function has the effect of organising space and the lived experience, such that it fits into a specific agenda (ibid.).

Katz says that power appears in the form of a "visible monumentality [that] is built on rendering invisible those who are on the losing end of the great and growing divide between rich and poor" (2001: 103). Lefebvre explains that in regards to power, space "implies an ideology designed to conceal that use, along with the conflicts intrinsic to the highly interested employment of a supposedly disinterested knowledge" (1991: 9). Félix Guattari comments on this process of concealment in a similar way, but also includes a psychoanalytic approach. Making particular note of the university as a body of power, Guattari states: "universities and other such bodies develop an entire ideology and set of phantasies of repression in order to counter processes of social creation in every sphere" (1984: 34). Sigmund Freud describes the act of repression as coming about through something distressing that has occurred to the individual, which they are unable to cope with. In his list of causes he 
uses the word "shameful" (2007:17). He goes on to explain that much effort is required by the analyst in order to get to the core of the repression due to "the measure of resistance" by the analysand because the ego is repelled by approaching the issue at hand (2007:18). Freud describes repression as a "primary mechanism of defence" used as a way of protecting the ego (ibid.).

I maintain that the socio-historic narrative of St George's Field has become part of the unconscious of the university, such that it is a geographically repressed place. While the physical space still exists - space cannot be annihilated however much one represses it - it is not acknowledged by the university. It is not fully embraced as part of the campus, the campus history or the university heritage. It is repressed as a defence mechanism due to institutional shame, brought about through feelings of guilt and fear. In psychoanalysis repression compensates for the feelings of guilt by disavowing them, which then provides the individual with the ability to carry on, appearing to manage, despite the facets of themselves that are not fully integrated. And, since physical and psychoanalytical space are both topographical and/or topological, they create binary elements such as inside/outside and visible/invisible. This enables us to examine the geographical space in a similar way to the psyche.

The compensatory element is picked up by Foucault when describing space. When discussing heterotopias he discusses how the act of creating a space forms partitions that define both sides of these types of binaries. For example, by defining an illusory heterotopic space, we can reaffirm a real space: the heterotopia's purpose might be "to create a space that is other, another real space, as perfect, as meticulous, as well arranged as ours is messy, ill constructed, and jumbled" (2001: 243). Foucault describes these two types of spaces as heterotopias of "illusion" and "compensation" (ibid.). He offers up colonial space as an example of a heterotopia of compensation. The cemetery could be considered to be a colonially occupied space: a dilapidated space requiring organisation (order versus chaos) and cultivation (culture versus nature). The process of landscaping then supports the repressive project of 'forgetting' (hiding): "the essence of repression lies in turning something away, and keeping it at a distance, from the conscious" (Freud 2007: 569-70), (Freud's italics). At one time cemeteries were the centre of the village, town or city, reflecting a religious community spirit. A more secular attitude, and a greater awareness of disease in Victorian times, meant cemeteries were moved to the suburbs. St George's Field confirms Foucault's 
second principle of the heterotopia, a historical place that has a determined position within culture, which can then be superseded by another function at a later time (2001: 243): the change of use from cemetery to garden. Alfredo González-Ruibal sees these redeveloped places as affecting time as well as space. He explains that they are a form of "temporal cleansing" which have "political consequences" (2016: 148). These spaces are out of time in regards to the moment of redevelopment. As well as a change of space occurring through their renewal, time is also affected: "Time accelerates, but not for everybody and not at the same pace." (2016: 150).

St George's Field not only holds true of the basic principles of what classifies a heterotopic space, it also has further qualities that a 'regular' cemetery might not. These further heterotopic qualities have come about because of its conditions for reuse set out in the 1960s. For example, as Foucault states in his third principle: "The heterotopia is capable of juxtaposing in a single real place several places, several sites that are in themselves incompatible" (ibid.). Is it possible for the cemetery to also be a garden? Can it comfortably be a sanctified place of rest for the dead and also a park-like area, open to all and contained within the boundaries and administrative structure of a university campus? These questions are posed not because I intend to answer them, but so as to highlight the tensions inherent in the place, these very tensions being what creates a heterotopia in the first place. Foucault describes these simultaneous places as being "foreign to one another" (2001: 238).

Alessandro Bonazzi explains the value of exploring postmodern spaces in this way. In his discussion on Edward Soja's explication of Foucault's theory of heterotopology, he looks at themes such as memory, reality versus representation, lines of site and surfaces. All these apply to the case study at hand - the cemetery. Bonazzi explains the value of using heterotopology as a form of analysis:

It is precisely this attempt which allows heteropology to become a useful instrument to investigate a postmodern space that is functional to a human geography and which, in turn, takes geography back to space itself. Soja understood heterotopia as a sort of compass that geographers could use to redraw their maps, to rediscover the logic of those forms that remain hidden behind the tabular forms of modernity. (2002: 42)

The "logic" described above, that of the modernist project, can be physically seen in the masterplan of the university development (it is a modernist project, after all) and is translated into the rhetoric surrounding the landscaping of the cemetery. Heterotopology "reveals the ideologies, the hidden knots" (Bonazzi 2002: 42) and enables a form of deconstructive analysis that exposes the contradictions inherent in space. It provides an examination that 
goes beyond the surface and that brings to light that which is hidden.

The tensions inherent in St George's Field reflect the dichotomies that are often present in postmodern space: such as old/modern, real/inauthentic, open/closed and absent/present. This highlights the complexity of the space and lends it to being described as palimpsest. St George's Field can be described in this way, not least because it has a history that can be traced back over nearly two hundred years, but also because of the history held in the ground in the form of the bodies still interred there, especially those that no longer have the gravestones that appear on the surface. The physical index to the location of the body is now absent: one could say it has been wiped off the surface off the land. As a palimpsest heterotopic space St George's Field reflects a "set of relations that delineates sites which are irreducible to one another and absolutely not superimposable on one another" (Foucault 2001: 239). While the paupers' graveyard has utopian origins in attempting to provide a burial place for everyone, these have become superseded in a culture where space not only has a high monetary value attached to it, but also can be acquired by others under the rubric of 'public benefit'. This demonstrates the potential conflicts in terms of land reuse, but also flags up the issues that can arise in the possible negation of histories that can be the result of the reuse of land, especially if its development takes place under a cloud of controversy.

Guattari acknowledges the problems attached to the representation of social history when it is considered to be "the site of the unconscious":

It is, in fact, impossible to systematize the real discourse of history, the circumstance that causes a particular phase or a particular signifier to be represented by a particular event or social group, by the emergence of an individual or a discovery, or whatever. (1984: 118)

He says that the complexity of historical events, in regard to cause and effect, are so complicated that providing a full account is impossible. Personal narratives can often be the only accounts available and, indeed, at one time they were the only markers of history, today making up parts of historical documents that have been enshrined as 'the truth'. Examples of personal narratives exist in the university archive in relation to St George's Field. One of the letters held there makes reference to the indexing of the graves once the gravestones had been removed. The letter, written on behalf of the relatives of a number of people buried there, said that university's grave records "were a fragment of what we know should be recorded" (Wolstencroft [year unknown]:2). It appears that the author of the letter, and their family, had moved away at some point and when later visiting the cemetery were distressed to find that 
their relatives' gravestones had gone (Wolstencroft [year unknown]:3). ${ }^{4}$

In discussing the history of knowledge and its validation, Foucault explains that there is no truth that can be accounted for outside of its own historical episteme, Foucault shows us these influences in the form of discursive formations that give rise to these epochs. 'Truth' is a function of a whole network of factors which form a specific utterance in the propagation of an individual statement. Statements exist in their moment of utterance, defined by their enunciative domain, materialised by their specific formalised mode of power, and supported in the materiality of this institution or that. So is it even fair to criticise the university for the acts of its past?

Nevertheless, I believe that the repressed parts of the university will continue to haunt it, will arise as dissonant elements and will appear as contradictions in the way it portrays itself. The university's disavowal means it does not fully see itself: "How do you recognize a ghost? By the fact it does not recognize itself in a mirror" (Derrida 1994:195). These hauntings, I argue, are because the past has not been put to rest in any acknowledged way, in the same way that it might be in the case of personal trauma. St George's Field is an example of this inasmuch as other than the University Library archives on the cemetery, my own and Fletcher's unpublished theses, the work by Julie Rugg and the Cemetery Research Group, and some links to the $\mathrm{BBC}$ website, there is no readily available information on this conflicted space. It is as if the university would prefer for it to have always been the landscaped park that it manifests as today.

The university 'turned its back' on the cemetery even before its conversion to a park: "[T]he existing buildings literally huddle round three sides of the Woodhouse cemetery" (CPB 1960: 37). This is not because it does not 'care' for it (it tends the lawns and maintains the remaining gravestones), but because it hides the cemetery. It hides its history and it hides the actual cemetery. The history of St George's Field requires determination and research skills in order to be discovered..$^{5}$ The cemetery itself is disguised under the grassy surface and situated in an enclave surrounded by buildings on all sides. The concealing is so skilful as to utilise the original cemetery wall as an architectural engineering component on which to balance, in a cantilever effect, the Henry Price Halls (see figure 5).

In 'The Haunting of the University: Phantomenology and the House of Learning' Gray Kochhar-Lindgren's deconstruction of higher education evokes the ghostly spectre of the past university still appearing in its contemporary form (in the same way that Bill Readings does 
in The University in Ruins 1996). What I have mooted as being the unconscious of the university, could be what Kochhar-Lindgren is describing in his haunted institution: "perhaps these inscribed memories and unloved potentialities of Romanticism are now coming to haunt us in the very depths of our self-conceptions, our attempt to absolutely privilege a capitalized ratio over all forms of the phantasm" (2009: 9), (Kochhar-Lindgren's italics). Although Kochhar-Lindgren's article is a deconstruction on the place of teaching, rather than the physical place of the university, the two cannot be separated. He expresses the relationship between them: "Phantomenology will come and go in its own rhythms along the folded edge between manifest and seeming, what has sometimes been called 'truth' and 'falsehoood', 'fact' and 'fiction', but the two are always inseparabl[e]" (2009: 8).

Lefebvre explains to us how abstract space (the space of capitalism) has the function of occluding time: "it is within space that time consumes and devours living beings", although he goes on to say that the "violence" occurring in this space does not always remain "hidden" (1991: 57). Abstract space is replete with incongruities as we can see with the apparently seamless park of St George's Field and the cemetery which underlies it. As Lefebvre explains: "Such spatial contradictions derive in part from the old contradictions thrown up by historical time. These have undergone modifications, however: some are aggravated, others blunted" (1991: 52). He goes on to say: "The reproduction of social relations of production within this space inevitably obeys two tendencies: the dissolution of old relations on the one hand and the generation of new relations on the other" (ibid.).

Today we have the redundancy of the old space of the cemetery being superseded by its new function as a university greenspace: the neoliberal project with its attempts at the homogenising of space. The university's representation of the cemetery, as a specific territory under its control, requires that it constantly manages its appearance (spatially and abstractly) in a specific way in order that its incongruences are not left open to criticism. But this repressed heterotopia threatens to return at every turn:

At the stage of the return of the repressed, it turns out that the self-reproach returns unaltered, but rarely in such a way as to draw attention to itself; for a while, therefore, it emerges as a pure sense of guilt without any content. It usually becomes linked with a content which is distorted in two ways - in time and in content: the former in so far as it relates to a contemporary or future action, and the latter in so far as it signifies not the real event but a surrogate chosen form the category of what is analogous - a substitution. (Freud 2007: 92), (Freud's italics)

If Freud is right about the return of the repressed in that it will reappear as something 
distorted, what form will the cemetery's re-emergence take in the psyche of the university? What will be its replacement or is the park as we see it today, this very replacement?

St George's Field is in a sense a double: it is both the cemetery and the park. The theme of the double is tied into the idea of death in Freud's discussion of the uncanny. He states: "The double was originally an insurance against extinction of the self" (2003: 142). The new space has simultaneously insured the continuation of the cemetery, even if its appearance has changed. Freud says that what eventually develops into the conscience forms a kind of authority which enables the old concept of the double - that which belongs to childhood "primordial narcissism" - to become something else (2003: 142). What the conscience does is "imbue the old idea of the double with a new content and attribute a number of features to it" (2003: 142-3). Under its redevelopment the cemetery is propagated with this new content, thus becoming something else. Through the double the university may be able to make sense of both the contradictions inherent in the physical space itself, and its own anxiety in regard to its involvement in the reneging of its promise to the relatives of the dead, thus dealing with its cognitive dissonance perfectly satisfactorily.

The institutional shame felt by the university has resulted in its attempts to hide the cemetery history by actually hiding the cemetery itself (it is also worth noting, that the origins of the word 'shame' come from European words that can be translated as 'to cover'). But St George's field is indestructible: "What is repressed is always destined to return - even if only in distorted fashion and in the form of a compromise" (Oring 1993: 290). The university also experiences fear in regard to this repressed space: the return of the repressed often reappears in the form of something fearful. Freud says that this process works as such because "every affect arising from an emotional impulse... is converted into fear by being repressed" (2003: 147). Repressed experiences have the need to return in other forms: "The greater the resistance, the more extensively will acting out (repetition) replace remembering" (Freud 2001: 151).

Nevertheless, the institutional resistance does not prevent the work of others in bringing the cemetery's history to light. Because of the complexity of the physical space and its fragmentary social history, it lends itself well to examination from many academic fields. González-Ruibal explains the value of a cultural theory approach to archaeological remains:

It seems that excavation, stratigraphy or ruins only become important at a transdisciplinary level when people from outside archaeology pay attention to them and 
somehow materialize them. This is due in part to the fact that people like Foucault and Freud have been able to see the enormous potential of these ideas as tropes to understand not just strange and dead cultures from the deep past, unconnected from current concerns, but human existence in general, modernity in particular, and the present. (2013: 1)

Here González-Ruibal is expressing the value of topological cultural approaches (both material and abstract) that look beyond appearances and examine both the structural and denotative signs contained in these spaces and what they might mean. These signs hover over the cemetery in a ghostly form, awaiting translation, their latent meaning pending.

The apparent 'naturalising' of the cemetery into a grassy park actually has the effect of phantomising St George's Field. The ghost of the cemetery that lies beneath the surface of the park constantly and quietly threatens the institution. Its voice - the collective voice of those buried there - is still whispering to us 'beyond the grave'. These voices have been suppressed: alternative voices are discouraged, revolutionary ones need to be crushed or at the very least assuaged through hegemonic means. Or, post event, they can be ignored entirely by being 'written out of history'. However, these other voices and histories are still part of the body that makes up the institution as it appears today, even if they might be side-lined, for strategic reasons or otherwise. If the university is not conscious of its past it would be difficult for it to think of itself as a place of community, of consensus or belonging. In order to confront its unconscious the university needs to come to terms with its past and present relationships, especially those that reveal incongruences. I would like to suggest that this can be done by looking for the concealed university, the one that is behind the veil of the manufactured image: the one that appears in the darkest parts of the university, in its archives and in its lost or hidden places. 


\section{References}

Acts of Parliament. (1966). University of Leeds Act 1965. In The local and personal acts 1965. London: Her Majesty's Stationery Office.

BBC. (2006). Life and death in Leeds. Retrieved from BBC website:

http://www.bbc.co.uk/leeds/content/articles/2006/04/24/local_history_general_cemetery_feat ure.shtml

Bonazzi, A. (2002). Heterotopology and geography: A reflection. Space and Culture, 5(1), 42-48.

Chamberlin, Powell and Bon. (1960). University of Leeds development plan. Leeds: The University of Leeds.

Chapman, M. J. Compensation for loss of burial rights. 12 July 1973.

Derrida, J. (1994). The Specters of Marx: The state of the debt, the work of mourning and the new international. Trans. by Kamuf P. Routledge: London and New York.

Fischler, R. (1995). Strategy and history in professional practice: Planning as world making. In Liggett H. \& Perry D. C. (Eds.), Spatial practices (13-58). London: Sage.

Fletcher, R. F. (1975). The history of the Leeds General Cemetery Company 1833-1965 (unpublished doctoral thesis). University of Leeds.

Foucault, M. (2001). Of other spaces. In Mirzoeff N. (Ed.), The visual culture reader (237244). London: Routledge.

Freud, S. (2001). Remembering, repeating and working through. In The standard edition of the complete psychological works of Sigmund Freud volume XII. London: Vintage.

Freud, S. (2003). The uncanny. Trans. by McLintock D. London: Penguin Books.

Freud, S. (2007). The Freud reader. Ed. by Gay P. London: Vintage.

González-Ruibal, A. (2013). Reclaiming archaeology. In González-Ruibal, A. (Ed.), Reclaiming archaeology: Beyond the tropes of modernity (1-30). Abingdon: Routledge.

González-Ruibal, A. (2016). Archaeology and the time of modernity. Historical Archaeology, $50(3), 144-164$.

Guattari, F. (1984). Molecular revolution: Psychiatry and politics. Trans. by Sheed R. Harmondsworth: Penguin Books.

Harvey, D. (2006). Spaces of global capitalism: Towards a theory of uneven geographical development. London and New York: Verso.

Katz, C. (2001). Hiding the target: Social reproduction in the privatized urban environment. In Minca C. (Ed.), Postmodern geography: Theory and praxis (93-110). Oxford: Blackwell Publishers.

Kochhar-Lindgren, G. (2009). The haunting of the university: phantomenology and the house of learning. Pedagogy: Critical Approaches to Teaching Literature, Language, Composition and Culture, 9(1), 3-12.

Lefebvre, H. (1991). The production of space. Trans. by Nicholson-Smith D. Oxford: Blackwell. 
Miller, D. S., \& Rivera, J. D. (2006). Hallowed ground, place, and culture: The cemetery and the creation of place. Space and Culture, 9(4), 334-350.

Mullins, P. R. \& Jones L. C. (2011). Race, displacement, and twentieth-century university landscapes. In Barnes J. A. (Ed.), The materiality of freedom: Archaeologies of postemancipation life (250-262). Columbia: The University of South Carolina Press).

Oring, E. (1993). Victor Turner, Sigmund Freud, and the return of the repressed. Ethos, 21(3), 273-294.

Richardson, G.B. (1967). ‘Leeds General Cemetery’ 23 May 1967. (London Necropolis Company).

Wolstencroft, Charles and Emily. (year unknown). 'Incomplete Grave Records'. 25 July (year unknown).

\footnotetext{
${ }^{1}$ I use the term 'shame' here in the Freudian sense of the word, such that it relates to events that have caused an individual distress and that they are unable to come to terms with and, therefore, integrate with the ego. On an institutional level they can manifest as dissonance (contradictory behaviours, for instance, the sharing of knowledge versus university policies) or just a general discomfort around specific historical events that appear as a lack of transparency.

${ }^{2}$ Fletcher states that even a deteriorating cemetery might be better for the university than letting the space become acquired by another organisation (1975: 102).

${ }^{3}$ In regard to the removed gravestones: some were broken up and used as aggregate to form the undulating surface of the new park, some were located in nearby museum collections, and some of the paupers' gravestones were turned into paving stones for the new paths of the cemetery.

${ }^{4}$ They did, however, praise the university staff, who on their visit attempted to help as much as possible, even escorting them to the cemetery (Wolstencroft [year unknown]: 3 ).

${ }^{5}$ Apart from the BBC website, all the aforementioned sources are academic ones and therefore not available to the public in any accessible way.
} 